Keio J. Med. 27: 63-67, 1978

\title{
SARTORIUS MUSCULOCUTANEOUS FLAP IN THE REPAIR OF TROCHANTERIC PRESSURE SORE
}

\author{
YU MARUYAMA* and YASUYUKI HAMANO** \\ * Department of Plastic and Reconstructive Surgery, \\ School of Medicine, Keio University, Tokyo, Japan \\ * Department of Orthospaedic Surgery, Utsunomiya, \\ Saiseikai Hospital, Tochigi, Japan
}

\begin{abstract}
In large or recurrent trochanteric pressure sores with prominent bony involvement, absence of surrounding skin and subcutaneous tissue and with undurable, atrophic scars, excision of the greater trochanter and soft issue with the bursa creates large defects.

Ideally, the coverage of defects in this area should include the use of a flap of much involuted tissue, and blood supply should be autonomous and axial for reliability and healing potential.

In addition in these patients, one stage reconstruction is optimal, particularly if the donor defect can be closed primarily.

We used the sartorius musculocutaneous flap in the repair of trochanteric pressure sores in one stage without the resection of the bony prominence and gained good results.

Here in this paper we present the applied anatomy, the operative technique, and a typical case study.
\end{abstract}

\section{APPLIED ANATOMY}

The sartorius muscle is located between the superior-anterior iliac spine and the medical condyle of the tibia and acts as the extensor of the thigh.

The blood supply to this muscle is by numerous segmental vessels, but the main feeding vessel (ascending rames of $\mathrm{A}$. V. lateral circumflex femoris) into upper half of the sartorius muscle is located about $8 \mathrm{~cm}$ below the inguinal ligament and branches from the femoral artery and vein.

The blood supply to the skin and subcutaneous tissue of this area is derived from perforated vessels which exist on the superficial surface of the sartorius 
muscle, and it is possible to raise a musculocutaneous flap of $5 \times 16 \mathrm{~cm}$ maximum on a proximal base. ${ }^{1}$

\section{OPERATIVE TECHNIQUE}

Following total excision of the ulcer, the skin incision of the flap is begun $10 \mathrm{~cm}$ below the inguinal ligament on a slightly medial line between the anteriorsuperior iliac spine and the medial condyle of the tibia.

Incising the sartorius fascia medially, by blunt manual dissection, the sartorius muscle and overlying skin is elevated. After confirming the main feeding vessels, the lateral side of the skin and the fascia is severed. Then the distal end of the musculocutaneous flap is cut as long as is necessary to reach the defect.

Through a simultaneously-created subcutaneous tunnel, the flap is introduced to the defect. The muscle fibers and skin margins of this flap are sutured to the end of the defect and suction drains are placed under the donor and the recipient areas. The donor site of the flap does not require skin grafting.

\section{CASE STUDY}

A typical case study is shown in figures 1 to 5 .

\section{DISCUSSION}

Many surgeons who have long experiences in the repair of pressure sores have described that removal of the bony prominence is necessary for a long time favorable result..$^{2,3,4,5}$

The bony resection has disadvantages in that bleeding and oozing from the bone and that infection are possible, if it exposes the cancerous bone.

Ger commented in his paper that the muscular cushioning over the bony prominence renders the removal of the latter unnecessary. ${ }^{6}$

In our cases, the resection of the bony structure were not performed. The axial pattern myocutaneous flap, consisting of muscle, subcutaneous tissues and skin, has much more bulk and resistant padding than the muscle flap combined with split skin graft.

Additionally, we used the sartorius musculocutaneous flap for the repair of a trochanteric ulcer, because the area of a sartorius musculocutaneous flap does extend to the pubis and to the anterior spine of the iliac crest, ${ }^{7}$ the functional loss from its use is negligible, and the donor site of this flap can be closed primarily without any difficulty. 


\section{SUMMARY}

The sartorius musculocutaneous flap is quite useful for definitive immediate coverage of complex wounds within its territorial arc. A use and the details of this flap in one stage reconstruction of trochanteric pressure sore were described.

\section{REFERENCES}

1. McCraw, J. B. and Dibbell, D. G.: Experimental definition of independent myocutaneous vascular territories. Plast \& Reconstr. Surg. 60: 212-220, 1977

2. Conway, H. and Griffith, B. H.: Plastic Surgery for closure of decubitus ulcers in patients with paraplegia. American Journal of Surgery 91: 946-955, 1956

3. Ger, R.: The surgical management of decubitus ulcers by muscle transposition. Plastic \& Reconstr. Surgery 69: 1-7, 1971

4. Minami, T., Mills, R. and Parde, R.: Gluteus maximus myocutaneous kaps for repair of pressure sores Plast \& Reconstr Surg. 60: 242-249, 1977

5. Griffith, H.: The voice of polite dissent gluteus maximus myocutaneous flap for repair of pressure sores. Plast \& Reconstr. Surg. 60: 441, 1977

6. Ger, R. and Samuel, L.: Management of decubitus ulcers by muscle transplantation. Plast \& Reconstr. Surg. 58: 419-428, 1976

7. McGraw, J. B., Dibbell, D. G. and Carraway, J. N.: Clinical definition of independent myocutaneous vascular teritories. Plast \& Reconstr. Surg. 60: 341-352, 1977 


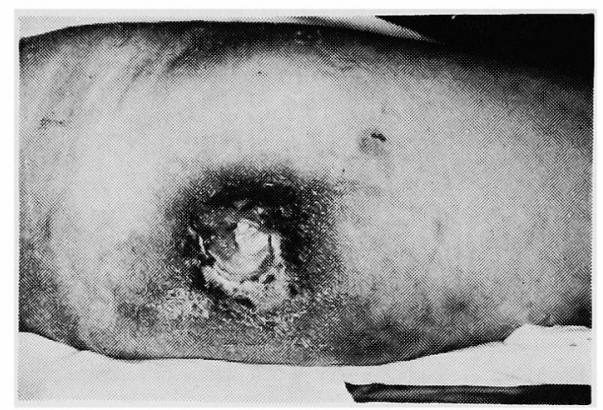

Fig. 1

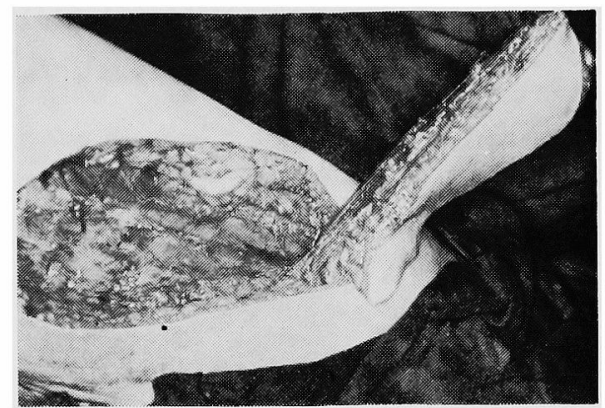

Fig. 2

Fig. 1 Preoperative view. A large trochanteric pressure sore with a bony prominence at the center in a paraplegic patient.

Fig. 2 The sartorius musculocutaneous flap was elevated. Good dermal bleedinfi at the distal end and smooth capillary refill was observed.

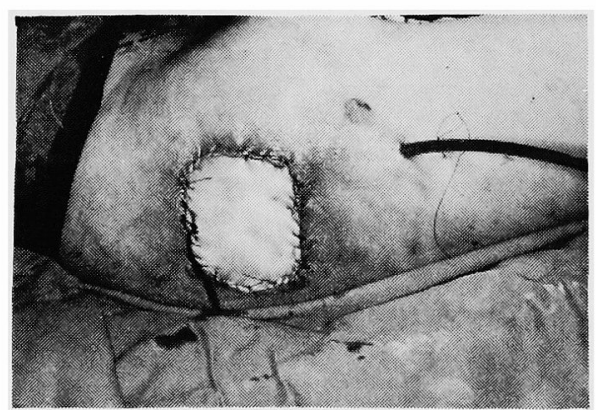

Fig. 3

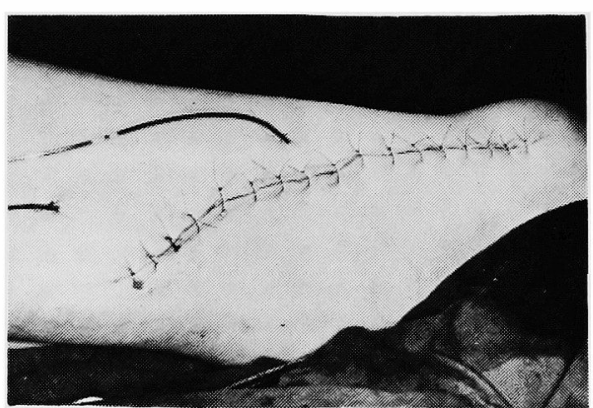

Fig. 4

Fig. 3 Through a subcutaneous tunnel, the flap was introduced to the defect created by adequate resection. Proximal excess skin of the flap was taken out.

Fig. 4 Primarily closed donor site.

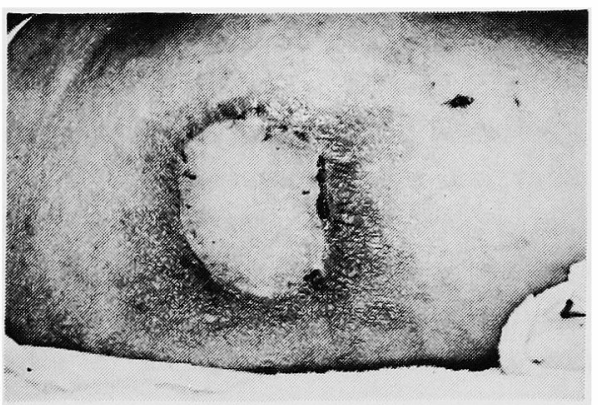

Fig. 5 Result, 3 months postoperative. 